\title{
Reply to the letter by Ben F. Bulten et al. regarding "Interobserver Variability of Heart-to-Mediastinum Ratio in I-123 MIBG Sympathetic Imaging"
}

\author{
Wengen Chen • Qi Cao • Vasken Dilsizian
}

Published online: 5 May 2012

(C) Springer Science+Business Media, LLC 2012

\section{To the Editor:}

We appreciate the favorable remarks by Dr. Bulten et al. regarding our article and proposed approaches for drawing region of interest (ROI) when computing heart-tomediastinal ratio (H/M ratio) in MIBG cardiac sympathetic imaging $[1,2]$. The authors applied two of our proposed approaches (the "whole heart ROI" and the "small anterior wall ROI") in 30 pediatric patients at their own institution, and verified that the use of both ROI definition methods in children provided an almost perfect interobserver agreement concerning $\mathrm{H} / \mathrm{M}$ ratio. In addition, they found very high intraclass correlation coefficients (ICCs) for both methods, although the "whole heart ROI" approach was better, and the within-patient ICC ratio was 0.865 . We concur with the suggestion that before selecting an approach for determining $\mathrm{H} / \mathrm{M}$ ratio in MIBG sympathetic imaging, it is important to consider the patient population studied. In pediatric patients, for example, in view of their relatively small heart size, the "whole heart ROI" is the preferred method. On the other hand, in adult patients with heart failure and dilated left ventricular cavity, the "whole heart ROI" method may underestimate the $\mathrm{H} / \mathrm{M}$ ratio due to the relatively high negative contribution of the myocardial cavity [1]. In the future, standardization of ROI placement methods should be an integral component of procedure guidelines for both adult and pediatric populations.

Thank you,

Wengen Chen, MD, PhD, Qi Cao, MD, PhD, and Vasken Dilsizian, MD

\section{References}

1. Chen W, Cao Q, Dilsizian V. Variation of Heart-to-Mediastinal Ratio in (123)I-mIBG Cardiac Sympathetic Imaging: Its Affecting Factors and Potential Corrections. Curr Cardiol Rep. 2011;13 (2):132-7.

2. Chen W, Botvinick EH, Alavi A, et al. Age-related decrease in cardiopulmonary adrenergic neuronal function in children as assessed by I-123 metaiodobenzylguanidine imaging. J Nucl Cardiol. 2008;15:73-9. 